\title{
A brief review of different types of sweat-gland carcinomas in the eyelid and orbit
}

This article was published in the following Dove Press journal:

OncoTargets and Therapy

II April 2013

Number of times this article has been viewed

\section{Leilei Zhang \\ Shengfang Ge \\ Xianqun Fan \\ Department of Ophthalmology, Ninth People's Hospital, Shanghai, People's \\ Republic of China}

Correspondence: Shengfang Ge/

Xianqun Fan

Department of Ophthalmology,

Ninth People's Hospital, Shanghai,

People's Republic of China

Tel +86 2I 63I3 5606/+86 2I 23271699 ext 5586

Fax +86 2I 63I3 7|48/+86 2I 6313 7|48

Email geshengfang@sjtu.edu.cn/

fanxq@sh163.net

\begin{abstract}
Sweat-gland carcinoma is a rare cutaneous appendage malignant tumor. Primary sweat-gland cancer can arise in the eyelid and orbit and is extremely rare. It has been classified into different types, and is usually locally recurrent after surgery. The tumors also appear in the orbit, which is characterized by metastasis. Therefore, great attention should be paid to the development of sweat-gland carcinomas. Specifically, our report briefly reviews the types of sweat-gland carcinomas that occur in the eyelid and orbit according to pathological classifications.
\end{abstract}

Keywords: spiroma, syringomatous carcinoma, mucinous eccrine carcinoma, clear-cell eccrine gland carcinoma, eccrine porocarcinoma, orbit

\section{Introduction}

According to anatomic characteristics and distributions, there are two classes of sweat glands: eccrine sweat glands and apocrine sweat glands. Eccrine sweat glands exist with different densities in different parts of the skin, although they are distributed throughout the body surface. Apocrine sweat glands are distributed in relatively limited regions of the body surface, mainly in the axilla and around the nipple, the perianal, and the perineum regions. The ceruminous gland in the external auditory canal and Moll's gland in the eyelid are also considered to be modified apocrine glands. Both benign and malignant tumors can develop in eccrine sweat glands or apocrine sweat glands. As reported, malignant tumor of the sweat gland is a rare cutaneous appendage. It has been classified into different types according to its pathology, and is usually locally recurrent after surgery. The tumors appear in the orbit, always characterized by metastasis. In addition, although some kinds of malignant tumor have different synonyms, they belong to the same type. In this review, different synonyms are sorted according to reported literature, and some common types of sweat-gland carcinomas are summarized based on clinical manifestations, treatment, recurrence, and metastasis. In the past, the low incidence and lack of awareness usually led practitioners to ignore these diseases. However, malignancy is extremely high in some types and patients, and will result in poor prognosis and even death for metastasis. We hope this review will be able to alert ophthalmologists or researchers to pay close attention to this kind of tumor and look for new and better treatments to improve prognosis of patients with high-grade malignant tumors.

\section{Syringoma}

Syringomas are common benign eccrine ductal adnexal tumors, mostly found in the periorbital area of middle-aged women. The women may be under the control 
of progesterone. Periorbital syringomas are aesthetically disturbing and difficult to treat. The strengthened activity of eccrine sweat glands results in excessive differentiation of sweat-gland ductal epithelial cells, which causes the formation of catheter obstruction. Periorbital syringoma as usually occur around the eyes, especially the inside part of the lower eyelid. Subsequently, some scattered papules will appear in the affected skin, which will not degrade for years and possibly even persist throughout the lifetime. These do not have an evident effect on human health. Many treatment modalities are used for aesthetics, such as topical and surgical methods, radiofrequency ablation, and carbon dioxide lasers.

\section{Malignant sweat-gland tumors of the eyelid}

According to the appearance and position of tumor cells, there are eccrine carcinomas and apocrine adenocarcinomas. Apocrine adenocarcinomas occur in accordance with apocrine glands, and therefore they can occur in the eyelid and areas of the skin rich with sweat glands in older people. ${ }^{1}$ They initially form at the skin surface with adhesion nodules or patches, which are often single but are sometimes multiple, are qualitatively hard, and can suddenly increase. They often have surface-skin adhesion, with normal skin-surface color or with the skin surface a little red. Some types of sweat-gland carcinomas relapse after surgery, and sometimes they metastasize to regional lymph nodes. Apocrine adenocarcinomas are considered to pursue a relatively indolent and protracted clinical course, with a few cases showing very aggressive biological behaviors. It should be emphasized that some cases of apocrine adenocarcinomas arising in the eyelid have the potential for rapid local growth, recurrence, and regional lymph-node and distant metastases. Eccrine carcinomas originate in eccrine glands, and mostly occur in the hair, face, eyelid, and limbs, such as the hands and feet. Invasive plaques, which can cause baldness, may occur on the scalp. Histopathologically, they are mainly classified into four classes: syringoid eccrine carcinoma, clear-cell eccrine gland carcinoma, mucinous eccrine carcinoma, and eccrine porocarcinoma (EPC). Of all the primary tumors of the sweat glands, except for mucinous eccrine carcinomas, they grow quickly with high rates of metastasis. In addition, there are uncommon types of adenocarcinomas, such as signet ringcell carcinoma (SRCC) and spindle-cell carcinoma. In many cases, other metastatic adenocarcinomas need to be ruled out, especially if accompanied by enlarged lymph nodes.

\section{Syringomatous carcinoma}

Syringomatous carcinoma (SC) has many variants or synonyms, including syringoid eccrine carcinoma (sometimes called eccrine SC), eccrine epithelioma (a basal cell tumor with eccrine differentiation), sweat-gland carcinoma with syringomatous features, and malignant syringoma microcystic adnexal carcinoma. ${ }^{2,3}$ The clinical features of SC are diverse, ranging from solitary solid nodules to multiple nodules, painful infiltrative plaques with alopecia areata, and prolonged ulcers similar to basal cell epithelioma. However, the most common feature is invasive plaques. Perineural and intraneural invasion is a common and a particularly characteristic finding in SC. This manifests as a malignant solid tumor originating in the eccrine glands, characterized by cutaneous involvement, skeletal muscle involvement, and perineural invasion. Under a microscope, obvious branched tubular structures can be seen. In accordance with the degree of tumor cell differentiation, the tumors can be divided into three types: including well, moderately, and poorly differentiated, the most common type being well differentiated. It is currently believed that due to different degrees of differentiation, there are different names for the same neoplastic process. Many patients have remained alive with this neoplasm for many years, because most SC is indolent and grows slowly.

Sex is equally distributed for occurrence of SC, and SC mainly occurs in the elderly (age range $20-80$ years). ${ }^{4,5}$ A worse prognosis is expected with older age. SCs are mostly found on the head and neck, with a predilection for the centrofacial region (about $85 \%$, mainly on the upper and lower lips). Less frequent sites include the eyebrow region, the nasolabial fold, nose, cheek, scalp, chin, and periorbital skin. ${ }^{6}$ A few cases showing very aggressive biological behaviors have also been reported; and, as a local aggressive developmental trend, the tumor often recurs after resection. It should be emphasized that some cases of SC arising in the eyelid have the potential for rapid local growth; however, regional lymph-node and distant metastasis is rare. Tumor cells can grow from the dermis to subcutaneous tissue invasively and can infiltrate around vascular structures and endanger the nervous system, accounting for disease recurrence. The disease was first described in 1969 by Freeman and Winkelmann. ${ }^{7}$ In the People's Republic of China, the first report was a case of eccrine gland carcinoma origined from Cheilion in 2011 at Kunming Medical College. ${ }^{8}$ There have been no other reports about syringoid eccrine carcinoma happening in the eyelid or orbit in the People's Republic of China. In the literature, $40 \%-60 \%$ of patients have been reported to have one or more local recurrences within 6 months to 30 years after treatment with standard wide local excision. ${ }^{5}$ In 2005, Hasegawa et al reported 14 cases of $\mathrm{SC}$, with five of these cases involving orbital content. All patients relapsed after surgical 
treatment. ${ }^{2}$ Currently, radiotherapy has been reported to be insufficient in treating this carcinoma. Primary microcystic adnexal carcinoma has been reported to recur 3 years after applying radiotherapy. ${ }^{9}$ In 2002 , after surgery, one patient had radiotherapy combined with chemotherapeutic agents and treatment with oxygen aniline; however, the recurrent tumors still developed. ${ }^{10}$ In 2005, Hasegawa et al suggested that wide excision of these tumors with a clear surgical margin using skull-base surgical techniques might offer a good prognosis. ${ }^{2}$

\section{Mucinous sweat-gland adenocarcinoma}

Primary mucinous sweat-gland adenocarcinoma of the eyelid (MSA) is an uncommon, slowly growing intradermal tumor of the eyelid with no clinically distinguishing features. The tumor may extend into the orbit and metastasize regionally. Surgical removal with continued regular follow-up examination is the treatment of choice. MSA most commonly locates on the head, and $47 \%$ of the patients with this carcinoma present with carcinoma in the eyelids. The average age for occurrence is 50-70 years, and there has been one case reported in a child. ${ }^{11}$ It was originally believed to have derived from the eccrine coil epithelium. However, apocrine differentiation has been demonstrated. ${ }^{12,13}$ Thus, the term "mucinous eccrine carcinoma" is seemingly inappropriate.

Pathological diagnosis is based on gland formation and small clumps of generally well-differentiated epithelial cells "floating" in large pools of basophilic mucin. Cancer cells are arranged in an adenoidal or cribriform fashion with mild atypia. Although it can relapse locally, it is a low-grade carcinoma with fewer metastases and a good prognosis. Recurrence is often related to a special tumor location and incomplete resection. For example, in the inner canthus, complete resection of the tumor is sometimes relatively difficult, and maintaining appearance and function is problematic. ${ }^{14}$ The recurrence rate of tumors located on the eyelids had traditionally been estimated at $40 \%$, based mainly on the study by Wright and Font in $1979 .{ }^{15}$ As recently as 2004, the estimated recurrence rate was $34 \%,{ }^{16}$ which was in accordance with the recurrence rate that was published in $1992 .{ }^{11}$ In 2010 , the recurrence rate was $26 \%$ after statistical analysis of 30 cases. ${ }^{17}$ During the same year, the recurrence of the tumor was reported as $30 \%$ by Segal et al. ${ }^{18}$ Generally, the recurrence rate has been between $26 \%$ and $40 \%$, which is worthy of attention. Of all these cases, ${ }^{18}$ the mean age of the patients was 61.3 years, and females accounted for $59 \%$. There were $44.2 \%$ located in the upper eyelid and $38.5 \%$ in the lower eyelid, while only $5.7 \%$ were in both eyelids, resulting in the conclusion that the probability that a single eyelid has a carcinoma is greater than the probability for both upper and lower eyelids. On the whole, the clinical appearance of mucinous sweatgland carcinomas of the eyelid is very variable. In many cases, the initial diagnosis was benign, including papilloma, neoplasm, chalazion, pyogenic granuloma, hemangioma and basal cell carcinoma. ${ }^{15,18-20}$ Segal et al ${ }^{18}$ reviewed that there were 12 patients misdiagnosed as benign, which accounted for $21.8 \%$ of the described 55 patients, and definite diagnoses of malignant tumours were made later. For an accurate diagnosis, it is essential to demonstrate that the neoplasm is clearly malignant. Histopathology is important in disease diagnosis. Primary MSA is uncommon, especially in the orbit. On the other hand, although primary MSA is invasive, it always has good results with a low malignancy rate. ${ }^{15}$ In 2008, Mortensen et al found that SRCCs primarily occurring in the eyelid have a relatively good prognosis. ${ }^{21}$ Metastatic lesions involving the orbit are uncommon, comprising $1 \%-13 \%$ of all orbital masses. ${ }^{22}$ After retrieval, except for those since 1971 , the reported cases of MSA in the orbit only accounted for $29.4 \%$, while metastatic mucinous sweat-duct carcinoma accounted for $70.6 \%(12 / 17) .{ }^{10,23-25}$ Of these cases, $41.7 \%$ $(5 / 12)$ originated in the gastrointestinal tract, being gastric cancer, colorectal cancer, colon cancer, and pancreatic cancer. It is noteworthy breast and ovarian cancer is most common in women wheras prostate cancer in male as described in Table 1. Therefore, histologically, the tumor may be identical to metastatic adenocarcinomas from the gastrointestinal tract, breast, ovary, lung, and pancreas. This is related to a higher gastrointestinal tumor incidence and common metastasis. Therefore, once MSA is confirmed, related gastrointestinal examination, female reproductive system tumors, and male prostate cancer need to be of concern. Primary and metastatic mucinous eccrine carcinomas are completely different. The latter has a stronger invasion ability and metastatic potential, so there is a completely different prognosis. Metastatic mucin-producing adenocarcinoma from the breast, the gastrointestinal tract, and ovary can present an identical histological appearance, although on occasion immunological markers may allow distinction. It has recently been discovered that a fetal antigen (alphafetoprotein), cancer antigen (CA)125, and CA19-9 are at high levels in most gastrointestinal tumors. For females, CA125 is elevated in ovarian carcinoma. A general imaging examination, including a chest X-ray, electrocardiogram, abdominal B-scan ultrasonography (liver, bile, spleen, pancreas, double kidney, and bladder), head computed tomography scan, postoperative magnetic resonance imaging, and positron emission tomography, to exclude systemic metastases is needed. There is also a need to distinguish carcinomas from benign lesions. Careful 
Table I Metastatic mucinous sweat gland carcinoma of the orbit

\begin{tabular}{|c|c|c|c|c|}
\hline Author (refs) & Year & Sex & Age & Primary carcinoma \\
\hline Monson et $\mathrm{al}^{22}$ & 2011 & M & 37 & Pancreatic adenocarcinoma \\
\hline Goodier et $\mathrm{al}^{26}$ & 2010 & $\mathrm{~F}$ & 68 & Breast cancer \\
\hline Asproudis et $\mathrm{al}^{27}$ & 2004 & $\mathrm{~F}$ & 34 & Breast carcinoma \\
\hline Yunker et $\mathrm{al}^{28}$ & 2006 & $\mathrm{~F}$ & 69 & Gastric adenocarcinoma \\
\hline Tanaka et $\mathrm{al}^{29}$ & 2006 & $\mathrm{~F}$ & 72 & Rectal adenocarcinoma \\
\hline Hisham et $\mathrm{al}^{30}$ & 2006 & $\mathrm{~F}$ & 32 & Rectum adenocarcinoma \\
\hline Onec et $\mathrm{al}^{31}$ & 2007 & M & 34 & Colon carcinoma \\
\hline Kaur et $\mathrm{al}^{32}$ & 2005 & $\mathrm{~F}$ & 60 & Mastectomy \\
\hline Heerema et $\mathrm{al}^{33}$ & 2001 & $M$ & 39 & Ovarian carcinoma \\
\hline Boor et $\mathrm{al}^{34}$ & 1996 & $\mathrm{~F}$ & 33 & $\begin{array}{l}\text { Intestinal-type sinonasal } \\
\text { adenocarcinoma }\end{array}$ \\
\hline Sher et $\mathrm{al}^{35}$ & 1983 & $M$ & unknown & Prostatic carcinoma \\
\hline Schill et $\mathrm{al}^{36}$ & |97| & M & unknown & prostatic carcinoma \\
\hline
\end{tabular}

preoperative diagnosis and complete resection in surgery is vital for preventing tumor recurrence and metastasis.

Since the first report, surgical resection has been a priority treatment. Currently, Mohs micrographic surgery is the method of choice for eccrine carcinoma, if there is no evidence of multifocality or distant metastases. After follow-up in 46 patients by Segal et al, 14 cases had recurrence, which accounted for $30.4 \%$. This is a relatively high recurrence rate. ${ }^{18}$ Once the MSA was found, particularly with recurrent eyelid lesions, it must be defined as a metastatic disease or a primary MSA. Surgery and histological confirmation of full excision is vital to prevent local recurrence and possibly metastasis.

Notably, there is a special type of primary SRCC (PSRCC), which is a very unusual but distinctive clinicopathological entity. The first case was described by Rosen et al in $1975,{ }^{37}$ and 28 cases have been reported subsequently. ${ }^{38}$ PSRCC with a component of well-differentiated ductal carcinoma, but with a substantial number of signet-ring cells, has been classified as SRCC. The identification of signet-ring cells, defined as cells that contain a dominant cytoplasmic vacuole and an eccentrically deformed nucleus, is requisite to the diagnosis. In addition, histologically, PSRCC of the eyelid tends to infiltrate throughout the dermis and scatter in the subcutaneous and adjacent soft tissues. These features are also analogous to lobular carcinoma of the breast, specifically the histiocytoid variant of lobular carcinoma. Based on morphological as well as immunohistochemical features, both eccrine and apocrine differentiation have been suggested. However, some controversy still exists about the exact histogenesis of these uncommon neoplasms. Gross cystic disease fluid protein 15 (GCDFP-15), lysozyme, and CD-15 have been proposed as specific markers for apocrine differentiation. ${ }^{39}$ Recently, many authors accept their apocrine nature because of their periodic
acid-Schiff-positive ${ }^{40}$ diastase-resistant secretions and immunoreactivity for grosscystic disease fluid protein 15 , but this is controversial because the antigen is demonstrated in normal eccrine glands. ${ }^{41}$ Whether GCDFP-15 is specific for apocrine tumors is currently under discussion. Regardless, GCDFP-15 is very useful for distinguishing between primary and metastatic adenocarcinomas of the skin. ${ }^{13,21,38}$ Because this antigen is also found in mammary and salivary glands, PSRCC of the eyelid is a rare locally aggressive tumor that predominantly affects elderly men. ${ }^{38}$ PSRCC may follow an extremely indolent course, but will eventually cause tissue destruction. Also, recurrences are common. Tanboon et al found that seven of 28 patients developed metastases. ${ }^{38}$ Therefore, metastatic mammary carcinoma must be excluded. The treatment is primary excision with histologic control of the excision margins in more advanced stages, and radiation therapy, neck dissection, and antiestrogen therapy should be considered. ${ }^{42}$ The most common metastatic sites are regional lymph nodes. The other reported metastatic foci are the skin of the head, neck, trunk, vulva, bone marrow, spine, and parotid gland. ${ }^{42-44}$ Most patients who have recurrence or metastasis have either incomplete tumor removal or orbital involvement. Thus, early detection and radical excision or exenteration is considered the preferred treatment of choice, but local radiotherapy may have a beneficial effect in retarding the spread of the disease. ${ }^{45}$ Adjuvant therapies such as radiotherapy or 5-fluorouracil chemotherapy have been proven to increase life expectancy. ${ }^{42,46}$ In axillary cases with a probable breast origin, estrogen and progesterone receptors chemotherapy are proposed, such as tamoxifen therapy, as is done in lobular infiltrating breast carcinoma. It is reported antiestrogen (tamoxifen) therapy has been used with some success as an adjunct treatment in advanced conditions. ${ }^{47}$ A 73 -yearold female patient received tamoxifen and postoperative irradiation and was disease-free for 18 months after surgery. ${ }^{12}$ Of course, there have also been other treatment modalities, including methotrexate, doxorubicin, cyclophosphamide, and 13-cis-retinoic acid. ${ }^{48}$ In summary, all these treatments have been attempted with varying success. But different treatments should be applied according to the condition of the patient. Once a malignant tumor has been diagnosed, it should be excised, and follow-up is necessary, if possible.

\section{Clear-cell eccrine gland carcinoma}

Sweat-gland carcinomas with clear-cell features are extremely rare, with few well-documented cases reported in the literature. Primary or metastatic clear-cell sweat-gland carcinomas occurring in the eyelid and orbit are mostly derived from the head, trunk, or the extremities. Keasby 
and Hadley first reported nodular hidradenocarcinoma as clear-cell eccrine carcinoma in $1954 .{ }^{48}$ Pathologically, it is rich in glycogen, vacuole bodies appear, and part of the cells' area had obviously eosinophilic cytoplasm. Owing to rich glycogen, clear cells showed diffuse positivity to PAS. PAS reactivity was related to the presence of clear cells. It is often misdiagnosed as another tumor or metastatic malignant tumor. In 2010, in the People's Republic of China, one case of clear-cell eccrine gland carcinoma originating in the scalp and then metastasizing to the orbit and spine was first reported. ${ }^{49}$ Firstly, it was diagnosed in ophthalmology, because of the prominent eye symptoms and signs. After being confirmed, the patient developed systemic metastasis and died soon after giving up treatment. Clear-cell eccrine carcinomas comprise a heterogeneous group of lesions that may range from locally recurring, low-grade, well-differentiated tumors to highly aggressive tumors. This cancer is reported as a lowgrade eccrine carcinoma representing a distinctive, albeit rare, subtype of adnexal neoplasm; however, it frequently recurs following surgical excision and has a high incidence of regional and distant metastases. ${ }^{50,51}$ Wide surgical excision is recommended as the primary treatment for such neoplasms. In the past, it has been reported that the tumors are radioresistant. ${ }^{48}$ But recently, it has been considered that radiotherapy may be effective in the treatment of such lesions. In Harari et al's cases, despite positive surgical margins, patients remained disease-free at 27 and 35 months after postoperative radiation..$^{52,53}$ The application of chemotherapy has not been considered, though it has been used. ${ }^{54}$

\section{Eccrine porocarcinoma}

EPC is regarded as the malignant counterpart of eccrine poroma and is mostly found on the lower extremities in elderly adults as a neoplasm arising from the intraepidermal portion of the eccrine sweat glands. The most common locations of EPC are the lower limbs, head and neck, trunk, vulva, breast, nail bed, and upper extremities. EPC is a distinctive form of malignant sweat-gland tumor, first reported in 1963 by Pinkus and Mehregan. ${ }^{55}$ Since then, there have been numerous cases reported, however the reported cases of EPC involving the eyelid are extremely rare.

Histopathologically, EPC demonstrates histological features suggestive of development from acrosyringium, and is characterized by sharply circumscribed islands and nests of atypical poromatous basaloid cells, glycogen granules within the tumor-cell cytoplasm, and lack of keratinization. A characteristic histological marker of EPC is the presence of many duct-like lumina that are formed either intracellularly or by the separation of neighboring cells. ${ }^{56} \mathrm{EPC}$ may occur de novo or as a malignant transformation of an eccrine poroma. Shaw et al found that long duration was typical in EPC, and in four cases the tumor had been present for 20 years or more, which suggested the possibility of malignant change arising from a preexisting benign eccrine poroma (BEP). ${ }^{56}$ This was supported clinically by long histories (mean 8.5 years $)^{57}$ and histological reports of dysplasia and malignant change in benign variants, including eccrine poroma and hidroacanthoma.$^{58}$ However, Robson et al reported occurrence of EPC in only $18 \%$ of cases of BEP. ${ }^{59}$ In addition, EPC that arises from BEP usually shows very slow progression. Very well-differentiated eccrine porocarcinoma may mimic BEP, yet there are certain morphological features that allow distinction, such as asymmetrical, poorly circumscribed and composed, variably sized and shaped cellular islands, which are often seen in EPC. ${ }^{60}$ Symptoms such as bleeding, pain, and itching are suggestive of a possible malignant transformation. Because the tumor has the capacity to metastasize, there is consequently a poor prognosis. There have been reports that about $20 \%$ of EPC will recur and about $20 \%$ will metastasize to regional lymph nodes. There is a mortality rate of $67 \%$ in patients with lymph-node metastases. ${ }^{61}$ In 2007, Shiohara et al reported that of twelve cases, $50 \%$ had lymph-node metastasis, with $33 \%$ dying of the disease. They also found lymph-node metastasis was correlated with lymphovascular invasion, and death was correlated with an infiltrative growth pattern and lymph-node metastasis. Finally, they suggested sentinel lymph-node biopsy might be useful in determining subclinical metastasis in the regional lymph nodes. ${ }^{62}$

The most accepted treatment of primary EPC is wide excision. Because EPC has a propensity for epidermal spread, excision with margin control is highly recommended. As for metastatic EPC, no standard therapeutic protocols exist. ${ }^{61}$ However, a variety of chemotherapeutics have been applied with varying degrees of response. A man developed metastasis after surgical excision of the primary tumor. He was then treated with lymphadenectomy, radiotherapy, and oral isotretinoin, which was subsequently substituted by tegafur, with no evidence of distant metastases after a 5.6-year followup. ${ }^{63}$ EPC is a rare malignancy of the eccrine sweat glands, but is curable if accurately diagnosed and properly treated.

Syringocystadenocarcinoma papilliferum is a type of sweat gland carcinoma. Hogust reviewed the reported 20 syringocystadenocarcinoma papilliferum cases and found that syringocystadenocarcinoma papilliferum did not have a high malignancy rate. Of 20 cases, only one relapsed, and two cases had regional lymph-node metastasis without 
distant metastases. ${ }^{64}$ Regarding syringocystadenocarcinoma papilliferum happening in the eyelid, there is only one case reported in the literature, without recurrence after 3-month follow-up. ${ }^{2}$ Also, in addition to eyelids, reports in other parts of the body are relatively infrequent. Because no other cases of syringocystadenocarcinoma papilliferum have been described to date in the ocular adnexal skin, its clinical behavior and treatment at this site are not well defined. The current knowledge of this tumor in other cutaneous locations, however, suggests that this lesion should be treated with conservative excision and close patient follow-up.

\section{Discussion}

At present, it is important to have basic knowledge of this disease process as a differential diagnosis, due to the limited number of reports and documented cases. According to histopathology, there are many types of sweat-gland carcinomas. Distinguishing sweat-gland carcinomas may be problematic, however, different types have different clinical manifestations, with different diagnoses and prognoses. The low incidence and lack of awareness usually lead practitioners to ignore this disease. Although some types have a good prognosis, great importance should be attached to pathological diagnostic classification. We provide a brief summary in Table 2.

$\mathrm{SC}$ is a slowly growing adnexal tumor with rare regional or distant metastases, and the well-differentiated form is found more frequently than the other two forms: moderately and poorly differentiated. The rate of tumor recurrence is high, reflecting extensive perineural invasion. Because radiotherapy and chemotherapy have been reported as insufficient to treat this carcinoma, wide surgical excision, which may be wider and deeper than anticipated, should be applied for the treatment of SCs arising in the eyelid. Sometimes, wide surgical excision using skull-base surgical techniques should be considered, although these are not widely used.

Primary mucinous adenocarcinoma is a rare, low-grade malignant tumor arising preferentially on the head and neck, especially in the eyelids. There are no clinically distinguishing features. The clinical appearance of mucinous sweat-gland carcinoma of the eyelid is very variable, manifesting as a chalazion, papilloma, neoplasm, pyogenic granuloma, or hemangioma. A definite diagnosis needs histopathologic examination. It has been considered to have high rates of recurrence (up to $40 \%$ ). ${ }^{15}$ However, when contemporary patient-management protocols using Mohs surgery or excision with frozen section control are used, the rates of recurrence are lowered to $26 \%{ }^{61}$ So a complete excision with histological confirmation of negative surgical margins of resection is required to reduce the chances of a recurrence. Adjuvant radiation has been suggested, ${ }^{65}$ though not widely.

As for mucinous sweat-duct carcinomas, we know most that arise in the orbit are metastatic tumors. Histologically, it may be both impractical and very difficult to distinguish metastatic mucinous adenocarcinoma from primary entities. Therefore, once diagnosed as mucinous sweatduct carcinomas, a workup to rule out metastatic lesions is necessary in all patients with cutaneous mucinous carcinoma. In female breast cancer, reproductive organ cancers should also be excluded, and in male patients, attention needs to be paid to exclude prostate cancer.

Clear-cell hidradenocarcinoma is an extremely rare eccrine neoplasm. Only a few cases of this type have been reported, always present in the head and neck. Recent literature has described the tumor occurring at a diverse range of sites, including the scalp, lip, breast, and vulva, but uncommon. Clear-cell hidradenoma may occasionally show mild focal cytological atypia and increased mitotic activity. Hence, any tumor with brisk mitotic activity and infiltrating growth should be reported with caution and a wide excision is recommended. PAS reactivity is related to the presence of clear cells. If there is distant metastasis, radiotherapy and chemotherapy may be considered.

EPC is a rare neoplasm. It may arise de novo; however, it usually develops on the long-standing site of eccrine poroma. Though the lower limbs are the most common site, it does occur in the eyelid and orbit. Although there has not been agreement reached about EPC arising from a BEP, it can happen that EPC can arise from BEP, which is noteworthy of a possible malignant transformation. The first recommended treatment of primary EPC is wide excision. Also, we can use sentinel lymph-node biopsy to determine if subclinical metastasis is in the regional lymph nodes. Radiotherapy and chemotherapy can be used as adjuvant therapy. Treatment for the metastatic disease has not been standardized. Neither chemotherapy nor radiation therapy has been proven to be of clinical benefit in treating metastatic disease. Management of EPC using a therapeutic approach involving surgery and ECT in case of regional metastatic spread has been reported. ${ }^{61}$

The mainstay of treatment from the first to the most recent reports has been surgical excision. Therefore, early pathological diagnosis and early wide excision are especially important. The regions with high lymphatic metastasis intensity should be dissected. Even for relapsing cases, positive comprehensive treatment measures should 


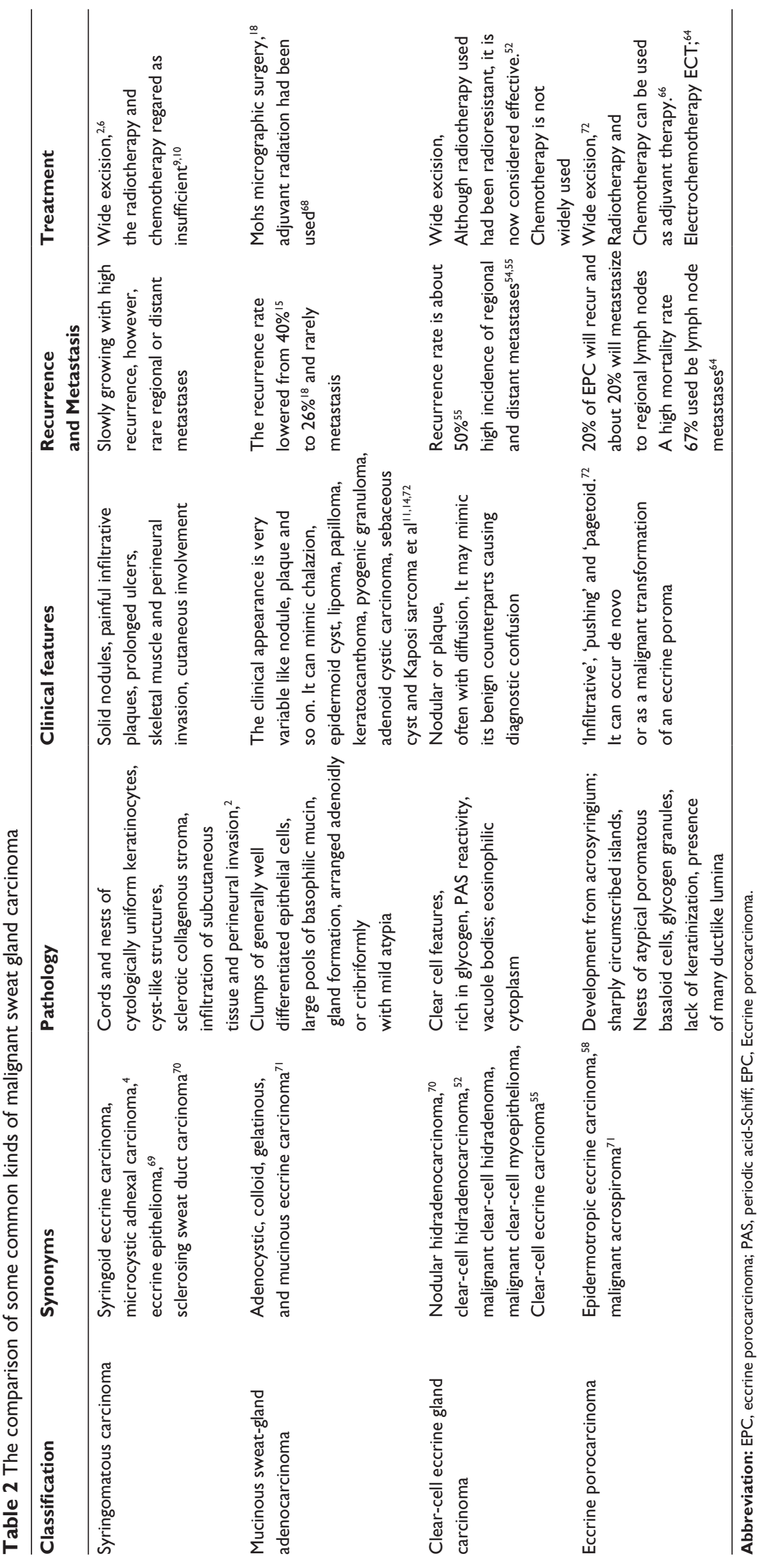


be taken to prolong survival, and ophthalmologists should consider surgery. In addition, many methods should be used to treat these tumors. The cause of sweat-gland carcinomas not sensitive to chemotherapy drugs must be studied, as well as optimization of the surgical method, maintaining appearance and wide surgical resection of the tumor to prevent recurrence. At present, the cellular and molecular mechanisms of sweat-gland carcinoma are rarely discussed, which urgently needs to be explored. Correct diagnosis and complete surgical resection are effective means to prevent tumor recurrence. During the last decade, Mohs micrographic surgery has been used frequently, although other surgical methods have also been used. In 2005, Hasegawa et al suggested that wide excision of these tumors with a clear surgical margin using skull-base surgical techniques might offer a good prognosis. ${ }^{2}$ However, this option may not be widely used. Radiotherapy has been used as a supplement to surgical excision in patients with multiple recurrences, and has been successful in some cases. In general, improving the treatment and prognosis of sweat-gland carcinoma in the future needs the joint efforts of all of us, ophthalmologists and researchers. All in all, a timely recognition, a correct initial histological interpretation of lesions, a standard surgical excision with free margins of the excised tissue can decrease the risk of recurrence, morbidity, and mortality, which portends a favorable prognosis.

\section{Acknowledgments}

This work was supported by a National Natural Science Foundation of China grant (81172323), a Shanghai Leading Academic Discipline Project grant (S30205), the Science and Technology Commission of Shanghai (10JC1409100, 12ZR1417300), and the Shanghai Rising-Star Program (11QA1404000).

\section{Disclosure}

The authors report no conflicts of interest in this work.

\section{References}

1. Shintaku M, Tsuta K, Yoshida H, Tsubura A, Nakashima Y, Noda K. Apocrine adenocarcinoma of the eyelid with aggressive biological behavior: report of a case. Pathol Int. 2002;52(2):169-173.

2. Hasegawa S, Kohmura E, Ichinose A, et al. Aggressive syringomatous carcinoma of the orbit. Skull Base. 2005;15(4):275-279.

3. Nishizawa A, Nakanishi Y, Sasajima Y, Yamazaki N, Yamamoto A. Syringoid eccrine carcinoma with apparently aggressive transformation: case report and review of the literature. Int $J$ Dermatol. 2006;45(10):1218-1221.

4. Goldstein DJ, Barr RJ, Santa Cruz DJ. Microcystic adnexal carcinoma: a distinct clinicopathologic entity. Cancer. 1982;50(3):566-572.

5. Sebastien TS, Nelson BR, Lowe L, Baker S, Johnson TM. Microcystic adnexal carcinoma. J Am Acad Dermatol. 1993;29(5 Pt 2):840-845.
6. Hoppenreijs VP, Reuser TT, Mooy CM, de Keizer RJ, Mourits MP. Syringomatous carcinoma of the eyelid and orbit: a clinical and histopathological challenge. Br J Ophthalmol. 1997;81(8):668-672.

7. Freeman RG, Winkelmann RK. Basal cell tumor with eccrine differentiation (eccrine epithelioma). Arch Dermatol. 1969;100(2): 234-242.

8. Liu TY, Chai YJ, Li X, et al. Syringoid eccrine carcinoma: the first case report in china. Chin J Dermatovenereol. 2011;25(4):247-249.

9. el-Domeiri AA, Brasfield RD, Huvos AG, Strong EW. Sweat gland carcinoma: a clinico-pathologic study of 83 patients. Ann Surg. 1971;173(2):270-274.

10. Kramer TR, Grossniklaus HE, McLean IW, et al. Histiocytoid variant of eccrine sweat gland carcinoma of the eyelid and orbit: report of five cases. Ophthalmology. 2002;109(3):553-559.

11. Snow SN, Reizner GT. Mucinous eccrine carcinoma of the eyelid. Cancer. 1992;70(8):2099-2104.

12. Langel DJ, Yeatts RP, White WL. Primary signet ring cell carcinoma of the eyelid: report of a case demonstrating further analogy to lobular carcinoma of the breast with a literature review. Am J Dermatopathol. 2001;23(5):444-449.

13. Gonzalez-Lois C, Rodriguez-Peralto JL, Serrano-Pardo R, Martinez-Gonzalez MA, Lopez-Rios F. Cutaneous signet ring cell carcinoma: a report of a case and review of the literature. Am J Dermatopathol. 2001;23(4):325-328.

14. Cohen KL, Peiffer RL, Lipper S. Mucinous sweat gland adenocarcinoma of the eyelid. Am J Ophthalmol. 1981;92(2):183-188.

15. Wright JD, Font RL. Mucinous sweat gland adenocarcinoma of eyelid: a clinicopathologic study of 21 cases with histochemical and electron microscopic observations. Cancer. 1979;44(5):1757-1768.

16. Marra DE, Schanbacher CF, Torres A. Mohs micrographic surgery of primary cutaneous mucinous carcinoma using immunohistochemistry for margin control. Dermatol Surg. 2004;30(5):799-802.

17. Papalas JA, Proia AD. Primary mucinous carcinoma of the eyelid: a clinicopathologic and immunohistochemical study of 4 cases and an update on recurrence rates. Arch Ophthalmol. 2010;128(9): $1160-1165$.

18. Segal A, Segal N, Gal A, Tumuluri K. Mucinous sweat gland adenocarcinoma of the eyelid - current knowledge of a rare tumor. Orbit. 2010;29(6):334-340.

19. Nizawa T, Oshitari T, Kimoto R, et al. Early-stage mucinous sweat gland adenocarcinoma of eyelid. Clin Ophthalmol. 2011;5:687-689.

20. Zhang Q, Wojno TH, Fitch SD, Grossniklaus HE. Mucinous eccrine adenocarcinoma of the eyelid: report of 6 cases. Can J Ophthalmol. 2010;45(1):76-78.

21. Mortensen AL, Heegaard S, Clemmensen O, Prause JU. Signet ring cell carcinoma of the eyelid - the monocle tumour. APMIS. 2008;116(4): 326-332.

22. Monson BK, Patel BC, Kim CH. Metastatic mucinous adenocarcinoma of the orbit. Orbit. 2011;30(1):18-20.

23. Cabell CE, Helm KF, Sakol PJ, Billingsley EM. Primary mucinous carcinoma in a 54-year-old man. $J$ Am Acad Dermatol. Nov 2003; 49(5):941-943.

24. Friednash M, Golitz L, Bohlmeyer T. Periorbital solitary nodule and multiple small papules in a 63-year-old women. Primary mucinous carcinoma (nodule) and syringom (papules). Arch Dermatol. Sep 1997;133(9):1161-1164.

25. Holds JB, Haines JH, Mamalis N, Anderson RL, Wolin MJ. Mucinous adenocarcinoma of the orbit arising from a stable, benign-appearing eyelid nodule. Ophthalmic Surg. Mar 1990;21(3):163-166.

26. Goodier MA, Jordan JR. Metastatic breast cancer to the lower eyelid. Laryngoscope. 2010;120 Suppl 4:S129.

27. Asproudis I, Gorezis S, Charalabopoulos K, Stefaniotou M, Peschos D, Psilas K. Breast carcinoma metastasis to the orbit and paranasal sinuses: a case report. Exp Oncol. 2004;26(3):246-248.

28. Yunker JJ, Vicinanzo MG, Braswell RA, Read RW, Goldin GF, Long JA. Unusual presentation of gastric adenocarcinoma metastatic to the orbit. Ophthal Plast Reconstr Surg. 2006;22(6):490-491.

29. Tanaka K. A case of metastases to the paranasal sinus from rectal mucinous adenocarcinoma. Int J Clin Oncol. 2006;11(1):64-65. 
30. Hisham RB, Thuaibah H, Gul YA. Mucinous adenocarcinoma of the rectum with breast and ocular metastases. Asian J Surg. 2006;29(2):95-97.

31. Oneç B, Oksüzoğlu B, Hatipoğlu HG, Oneç K, Azak A, Zengin N. Cavernous sinus syndrome caused by metastatic colon carcinoma. Clin Colorectal Cancer. 2007;6(8):593-596.

32. Kaur G, Ismail R, Harun H. Metastatic mucinous carcinoma of the eyelid. Malays J Pathol. 2005;27(2):117-118.

33. Heerema A, Sudilovsky D. Mucinous adenocarcinoma of the ovary metastatic to the eye: report of a case with diagnosis by fine needle aspiration biopsy. Acta Cytol. 2001;45(5):789-793.

34. Boor A, Jurkovic I, Dudrikova K, Kavecansky V, Friedmann I. Intestinaltype sinonasal adenocarcinoma: a sporadic case. J Laryngol Otol. 1996;110(8):805-810.

35. Sher JH, Weinstock SJ. Orbital metastasis of prostatic carcinoma. Can J Ophthalmol. 1983;18(5):248-250.

36. Schill J. [Rare metastasis of prostatic carcinoma in the orbit.] Zentralbl Chir. 31 1971;96(31):1063-1066. German.

37. Rosen Y, Kim B, Yermakov VA. Eccrine sweat gland tumor of clear cell origin involving the eyelids. Cancer. 1975;36(3):1034-1041.

38. Tanboon J, Uiprasertkul M, Luemsamran P. Signet-ring cell/histiocytoid carcinoma of the eyelid: a case report and review of the literature. $A m$ J Dermatopathol. 2012;35(1):e1-e5.

39. Ansai S, Koseki S, Hozumi Y, Kondo S. An immunohistochemical study of lysozyme, CD-15 (Leu M1), and gross cystic disease fluid protein-15 in various skin tumors. Assessment of the specificity and sensitivity of markers of apocrine differentiation. Am J Dermatopathol. 1995;17(3):249-255.

40. Mazoujian G, Margolis R. Immunohistochemistry of gross cystic disease fluid protein (GCDFP-15) in 65 benign sweat gland tumors of the skin. Am J Dermatopathol. 1988;10(1):28-35.

41. Kiyohara T, Kumakiri M, Kouraba S, Tokuriki A, Ansai S. Primary cutaneous signet ring cell carcinoma expressing cytokeratin 20 immunoreactivity. J Am Acad Dermatol. 2006;54(3):532-536.

42. Bellman B, Gregory NA, Silvers D, Fountain KS. Sweat gland carcinoma with metastases to the skin: response to 5-fluorouracil chemotherapy. Cutis. 1995;55(4):221-224.

43. Whittington R, Browning ME, Farrell GR, Miremadi A. Radiation therapy and chemotherapy in malignant sweat gland tumors. J Am Acad Dermatol. 1986;15(5 Pt 2):1093-1097.

44. Swanson PE, Cherwitz DL, Neumann MP, Wick MR. Eccrine sweat gland carcinoma: an histologic and immunohistochemical study of 32 cases. J Cutan Pathol. 1987;14(2):65-86.

45. Jakobiec FA, Austin P, Iwamoto T, Trokel SL, Marquardt MD, Harrison W. Primary infiltrating signet ring carcinoma of the eyelids. Ophthalmology. 1983;90(3):291-299.

46. Kuno Y, Tsuji T, Yamamoto K. Adenocarcinoma with signet ring cells of the axilla: two case reports and review of the literature. J Dermatol. 1999;26(6):390-395.

47. Wollensak G, Witschel H, Bohm N. Signet ring cell carcinoma of the eccrine sweat glands in the eyelid. Ophthalmology. 1996;103(11):1788-1793.

48. Keasbey LE, Hadley GG. Clear cell hidradenoma: report of three cases with widespread metastases. Cancer. 1954;7(5):934-952.

49. Song YQ, Liu R. A case of clear cell eccrine gland carcinoma firstly diagnosed in ophthalmology. Int J Ophthalmol. 2010;10(12):2414.

50. Orlandi RR, Sercarz JA, Doberneck SA, Calcaterra TC. Malignant clear cell hidradenoma of the upper lip. Head Neck. 1994;16(5):443-449.

51. Ohta M, Hiramoto M, Fujii M, Togo T. Nodular hidradenocarcinoma on the scalp of a young woman: case report and review of literature. Dermatol Surg. 2004;30(9):1265-1268.
52. Harari PM, Shimm DS, Bangert JL, Cassady JR. The role of radiotherapy in the treatment of malignant sweat gland neoplasms. Cancer. 1990;65(8):1737-1740.

53. Khalil HM, Yusuf H, Kaddour HS. Malignant eccrine hidradenoma of neck causing acute heart failure. Auris Nasus Larynx. 2003;30(3): 307-310.

54. Engel A, Bar-Dayan Y, Engelberg S, Levi Y. [Malignant nodular hidradenoma - sweat gland tumor.] Harefuah. 1999;136(9):683-686, 755. Hebrew.

55. Pinkus H, Mehregan AH. Epidermotropic eccrine carcinoma. A case combining features of eccrine poroma and Paget's dermatosis. Arch Dermatol. 1963;88:597-606.

56. Mehregan AH, Hashimoto K, Rahbari H. Eccrine adenocarcinoma. A clinicopathologic study of 35 cases. Arch Dermatol. 1983;119(2): 104-114.

57. Chang O, Elnawawi A, Rimpel B, Asarian A, Chaudhry N. Eccrine porocarcinoma of the lower extremity: a case report and review of literature. World J Surg Oncol. 2011;9:94.

58. Pylyser K, De Wolf-Peeters C, Marien K. The histology of eccrine poromas: a study of 14 cases. Dermatologica. 1983;167(5):243-249.

59. Robson A, Greene J, Ansari N, et al. Eccrine porocarcinoma (malignant eccrine poroma): a clinicopathologic study of 69 cases. Am J Surg Pathol. 2001;25(6):710-720.

60. Boynton JR, Markowitch W Jr. Porocarcinoma of the eyelid. Ophthalmology. 1997;104(10):1626-1628.

61. Marone U, Caraco C, Anniciello AM, et al. Metastatic eccrine porocarcinoma: report of a case and review of the literature. World $J$ Surg Oncol. 2011;9:32.

62. Shiohara J, Koga H, Uhara H, Takata M, Saida T. Eccrine porocarcinoma: clinical and pathological studies of 12 cases. J Dermatol. 2007;34(8):516-522.

63. Gonzalez-Lopez MA, Vazquez-Lopez F, Soler T, et al. Metastatic eccrine porocarcinoma: a 5.6-year follow-up study of a patient treated with a combined therapeutic protocol. Dermatol Surg. 2003;29(12): 1227-1232.

64. Hoguet AS, Dolphin K, McCormick SA, Milman T. Syringocystadenocarcinoma papilliferum of the eyelid. Ophthal Plast Reconstr Surg. 2012;28(1):e27-29.

65. Jih MH, Friedman PM, Kimyai-Asadi A, Goldberg LH. A rare case of fatal primary cutaneous mucinous carcinoma of the scalp with multiple in-transit and pulmonary metastases. J Am Acad Dermatol. 2005;52(5 Suppl 1):S76-S80.

66. McKee PH, Fletcher CD, Rasbridge SA. The enigmatic eccrine epithelioma (eccrine syringomatous carcinoma). Am J Dermatopathol. 1990;12(6):552-561.

67. Cooper PH, Mills SE, Leonard DD, et al. Sclerosing sweat duct (syringomatous) carcinoma. Am J Surg Pathol. 1985;9(6):422-433.

68. LeBoit PE, Burg G, Weedon D, Sarasin A. A Pathology and Genetics of Skin Tumors. Lyon, France IARCPress. 2006.

69. Liszauer AD, Brownstein S, Codere F. Mucinous eccrine sweat gland adenocarcinoma of the eyelid. Can J Ophthalmol. 1988;23(1):17-21.

70. Park HJ, Kim YC, CinnYW. Nodular hidradenocarcinoma with prominent squamous differentiation: case report and immunohistochemical study. J Cutan Pathol. 2000;27(8):423-427.

71. Gortler I, Koppl H, Stark GB, Horch RE. Metastatic malignant acrospiroma of the hand. Eur J Surg Oncol. 2001;27(4):431-435.

72. Belin E, Ezzedine K, Stanislas S, et al. Factors in the surgical management of primary eccrine porocarcinoma: prognostic histological factors can guide the surgical procedure. Br J Dermatol. 2011;165(5): 985-989. 


\section{Publish your work in this journal}

OncoTargets and Therapy is an international, peer-reviewed, open access journal focusing on the pathological basis of all cancers, potential targets for therapy and treatment protocols employed to improve the management of cancer patients. The journal also focuses on the impact of management programs and new therapeutic agents and protocols on patient perspectives such as quality of life, adherence and satisfaction. The manuscript management system is completely online and includes a very quick and fair peer-review system, which is all easy to use. Visit http://www.dovepress.com/testimonials.php to read real quotes from published authors.

Submit your manuscript here: http://www.dovepress.com/oncotargets-and-therapy-journal 